\title{
Prognostic and predictive clinical factors in patients with metastatic castration-resistant prostate cancer treated with cabazitaxel
} Daniel W. Yokom ${ }^{1}$; John Stewart ${ }^{2}$; Nimira S. Alimohamed ${ }^{3}$; Eric Winquist ${ }^{4}$; Scott Berry ${ }^{5}$, Stacey Hubay ${ }^{6}$; Jean-Baptiste Lattouf ${ }^{7}$; Helene Leonard $^{8}$; Carla Girolametto $^{9}$, Fred Saad $^{10}$; Srikala S. Sridhar ${ }^{1}$

${ }^{1}$ Princess Margaret Cancer Centre, Toronto, ON; ${ }^{2}$ Sanofi Canada, Montreal, QC; ${ }^{3}$ Tom Baker Cancer Centre, Calgary, ON; ${ }^{4}$ London Health Sciences Centre, London, ON; ${ }^{5}$ Sunnybrook Health Sciences Centre, Odette Cancer Centre, Toronto, ON; ${ }^{6}$ Grand River Regional Cancer Centre, Kitchener, ON; ${ }^{7}$ Division or Urology, Centre Hospitalier de l’Université de Montréal (CHUM), Montreal, QC; ${ }^{8} \mathrm{CHUM}$ Notre-Dame Hospital, Montreal, QC; ${ }^{9}$ Grand River Regional Cancer Centre, Kitchener, ON; ${ }^{10}$ Division or Urology, Centre Hospitalier de l’Université de Montréal (CHUM), Montreal, QC; Canada

Funding: This study was supported by Sanofi Canada

Cite as: Can Urol Assoc J 2018 April 6; Epub ahead of print. http://dx.doi.org/10.5489/cuaj.5108

Published online April 6, 2018

\section{Abstract}

Introduction: Cabazitaxel is one of several treatment options available for patients with metastatic castration-resistant prostate cancer who have progressed on docetaxel. Little is known about clinical factors that influence prognosis or treatment response for patients receiving cabazitaxel. Identifying prognostic and predictive factors could contribute to the optimal selection of patients for treatment after docetaxel.

Methods: A retrospective review of patients enrolled on the cabazitaxel Canadian Early Access Program (C-EAP) was performed. Clinical factors were analyzed by univariable and multivariable Cox proportional hazards and logistic regression analysis to identify independent predictors of prognosis and response.

Results: Forty-five patients from five centres in Canada were included in this study. On multivariable analysis, lower hemoglobin was associated with shorter survival. No other factors were independently associated with survival, prostate-specific antigen (PSA) response or primary PSA progression.

Conclusions: Clinical factors predicting survival or treatment response were not identified for men with castration-resistant prostate cancer receiving cabazitaxel. Larger studies may be necessary to identify clinical factors and biomarkers that identify whether patients should or should not receive cabazitaxel. 


\section{Introduction}

Prostate cancer is the most commonly diagnosed cancer in men and the third leading cause of cancer-related death in men in Canada and the United States. ${ }^{1,2}$ There are now several approved treatment options for patients with metastatic castration-resistant prostate cancer (mCRPC) progressing on docetaxel chemotherapy. ${ }^{3,4}$ Cabazitaxel is a novel tubulin-binding taxane with activity in taxane-resistant solid tumors. ${ }^{5}$ In the phase III TROPIC trial, cabazitaxel plus prednisone improved overall survival compared to mitoxantrone plus prednisone and became established as a standard second line treatment for mCRPC. ${ }^{6}$ Treatment with abiraterone, enzalutamide and radium-223 have also shown a survival advantage in this setting. ${ }^{7-9}$ Without head-to-head randomized controlled trials or sequencing studies, there is little evidence to guide which agent is best for a given patient and how the different agents should be sequenced to optimize outcomes. Until such data becomes available, identifying and understanding prognostic and predictive factors for patients progressing after first-line chemotherapy for mCRPC could aid patients and physicians with treatment decisions.

Prognostic factors correlate with outcome independent of treatment effect. Predictive factors inform on the probability of response to a treatment and therefore are more useful in helping clinicians determine whether a patient should be treated with a specific drug. Prognostic factors for mCRPC patients receiving first-line docetaxel are well-described and include: age, performance status, presence of visceral disease, hemoglobin, alkaline phosphatase (ALP), albumin, lactate dehydrogenase (LDH), prostate specific antigen (PSA) level, PSA doubling time, and Gleason score. ${ }^{10-17}$ For patients who receive second-line chemotherapy, an analysis of data from the TROPIC trial identified nine prognostic variables: Eastern Cooperative Oncology Group (ECOG) performance status, presence of pain, measurable disease, presence of visceral disease, time since last docetaxel use, duration of hormonal use, hemoglobin, PSA, and ALP. ${ }^{18}$ However, this analysis was limited in that it only included patients enrolled in the TROPIC trial at a time when abiraterone and enzalutamide were not commonly used. A further sub-analysis of the experimental arm of the TROPIC trial also identified severe neutropenia during treatment as a favourable prognostic factor. ${ }^{19}$ In a separate study of 47 patients treated with cabazitaxel, a pretreatment elevated neutrophil-to-lymphocyte ratio (NLR) greater than 3.83 was found to confer a worse prognosis with a HR of $3.0 .^{20}$ In routine clinical practice, little is known about the prognostic factors for patients receiving second-line chemotherapy including the impact of prior treatments.

Predictive factors for patients receiving chemotherapy for mCRPC are less well studied. A prospective study assessing the role of the androgen receptor splice variant 7 (AR-V7) as a predictive biomarker for patients with MCRPC showed that AR-V7 did not predict for response to taxanes, but AR-V7 positive patients had superior outcomes with the taxanes compared to abiraterone or enzalutamide. ${ }^{21}$ A sub-analysis of the experimental arm of the TROPIC trial identified that in addition to being a favorable prognostic factor, severe neutropenia was also a predictor of response. ${ }^{19}$ A high Gleason score $(>=8)$ was shown to correlate with increased progression-free survival in a small retrospective study. ${ }^{22}$ This would be consistent with the 
theory that more aggressive disease benefits from cabazitaxel. Multiple studies have also assessed the impact of prior abiraterone or enzalutamide on activity of cabazitaxel and all have shown that cabazitaxel continues to be active in this setting. ${ }^{23-27}$ Ultimately, there is insufficient evidence to know which clinical factors will predict for a response to cabazitaxel.

Given the dearth of information regarding prognostic and predictive factors for patients treated with cabazitaxel in routine clinical practice, we analyzed data from patients treated with cabazitaxel as part of the Canadian Early Access Program (C-EAP) to better understand routine clinical factors that may influence prognosis and identify which factors may predict for treatment response.

\section{Methods}

Inclusion criteria for enrollment in the C-EAP (NCT01254279) were: diagnosis of mCRPC, progression on or after treatment with docetaxel, ECOG performance status $\leq 2$, life expectancy $\geq 3$ months, and adequate bone marrow, cardiac, kidney and liver function. Exclusion criteria included active peripheral neuropathy or stomatitis. Patients were treated until disease progression, unacceptable toxicity, investigator's decision to discontinue treatment, or withdrawal of consent or death. Primary prophylaxis with granulocyte-colony stimulating factor (G-CSF) was permitted. ${ }^{26}$

Patients from four centres in Ontario and one in Quebec were included. Data from the CEAP was supplemented by a retrospective chart review including patient and disease factors, treatment factors and baseline laboratory values. Box 1 describes the variables which were collected and used in the statistical models.

Frequencies and percentages were used to describe patients' baseline characteristics, treatment exposure and grade 3-4 toxicities. Exploratory analyses were conducted to identify factors that predict for PSA response and PSA progression. PSA response was defined as reduction of baseline PSA by $\geq 50 \%$. PSA primary progression was defined as an increase in PSA by $\geq 25 \%$ by day 84 after the first dose of cabazitaxel and does not meet the criteria for PSA response. ${ }^{29}$ Each explanatory variable was analyzed by univariable logistic regression and Cox proportional hazard method for PSA response and survival, respectively. Variables were chosen for the multivariable models if $\mathrm{p}<0.15$ on univariable analysis. Model validation was performed using Hosmer and Lemeshow method. Data analysis was completed with Statistical Analysis Software (SAS) Version 9.3.

The C-EAP and this study were sponsored by Sanofi Canada.

\section{Results}

Forty-five patients enrolled in the C-EAP were included in this study. Median age was 65 years (range, 49 to 82 years), with 91.1\% of patients having an ECOG performance status of zero or one. Most patients had pain at the start of treatment (68.9\%). Only $22.2 \%$ of patients had visceral metastases and 58\% had bone-only disease. The median time since last dose of docetaxel was 9.4 months (range 0.7 to 56.8). One-third of patients previously used abiraterone. 
Primary prophylaxis with G-CSF was given to $53.5 \%$ of patients. Dose reductions were required in $28 \%$ and dose delays in 51\%. Median number of cycles was six (range, 1 to 27). For patients in the C-EAP the most common adverse events were neutropenia, anemia and fatigue. Grade 3-4 diarrhea occurred in 11\% of patients. Febrile neutropenia occurred in $9 \%$ of patients.

The PSA response rate was $45.2 \%$ with PSA progression as best response observed in $21.4 \%$ of patients. The follow-up period ranged from 3.4 to 38.7 months, during which time 37 deaths occurred (82.2\%) and median survival was 11.2 months.

Prognostic Factors

The impact of clinical factors on survival is described in Table 2. On univariable analysis, shorter time from last docetaxel cycle (HR 0.96, 95\% CI 0.91 to $1.01, \mathrm{p}=0.088$ ), requiring dose reductions (HR $0.54,95 \%$ CI 0.24 to $1.17, \mathrm{p}=0.118$ ), any grade 3-4 toxicity (HR 2.72, 95\% CI 1.17 to 6.33 , $\mathrm{p}=0.020$ ), and higher hemoglobin (HR 0.97, 95\% CI 0.94 to $0.99, \mathrm{p}=0.020$ ) had the largest impact on survival and were considered for the multivariable prognostic model. ECOG performance status, pre-treatment PSA, presence of pain, presence of visceral metastases, duration of hormonal use, and ALP did not significantly influence survival on univariable analysis. LDH was not considered, due to $\geq 5 \%$ missing values. To avoid over-fitting of the model, requirement for dose-reductions was not included in the final model. On multivariable analysis, only hemoglobin level had a statistically significant association with survival (adjusted HR 1.33 per 10 unit decrease in hemoglobin [95\% CI 1.05 to 1.62; p=0.047]). No other factors showed correlation with survival.

Predictive Factors

PSA Response

The effect of clinical variables on PSA response is described in Table 3. Univariable analysis for predictive factors identified three factors to be included in the multivariable model: the presence of visceral metastases (OR 4.85, 95\% CI 0.85 to 27.7; $\mathrm{p}=0.076$ ), primary prophylaxis with G-CSF (OR 4.06, 95\% CI 1.12 to 14.8; $\mathrm{p}=0.034$ ), and development of any grade 3-4 toxicity (OR 6.13, 95\% CI 1.98 to 34.35; $\mathrm{p}=0.039$ ). In the multivariable analysis, none were independent predictors of PSA response.

PSA Progression

Among patients enrolled in the C-EAP, only nine had primary PSA progression as defined in this study. The impact of clinical factors on primary progression is outlined in Table 4. On univariable analysis the factors which had the most significant impact on primary PSA progression were ECOG PS $\geq 2$ (OR 9.14, 95\% CI 0.72 to 115.5; $\mathrm{p}=0.09$ ), prior abiraterone (OR $0.10,95 \%$ CI 0.01 to $0.87 ; \mathrm{p}=0.04$ ), and receipt of primary prophylaxis with G-CSF (OR 0.08, $95 \%$ CI 0.01 to $0.73 ; \mathrm{p}=0.03$ ). Multivariable analysis was not performed due to the occurrence of less than 15 events. 


\section{Discussion}

\section{Prognostic factors}

In this study we present the first analysis of clinical prognostic and predictive factors for realworld patients with mCRPC receiving cabazitaxel. Among patients enrolled in the C-EAP, only low hemoglobin was associated with worse overall survival. This finding is consistent with previously published data on prognostic factors in patients receiving second-line chemotherapy for mCRPC. ${ }^{18}$ However, eight other factors previously identified as prognostic factors for patients receiving cabazitaxel (performance status, time interval since prior docetaxel use, presence of visceral disease, presence of pain, duration of hormonal treatments, PSA level, and ALP) were not found to be significant in the C-EAP cohort. Presence of visceral metastases has been shown to be strongly prognostic for patients receiving docetaxel, ${ }^{17}$ however, visceral metastases did not seem to influence prognosis for patients receiving cabazitaxel. Furthermore, there has been great interest in the role of markers of systemic inflammation as a prognostic factor for patients with mCRPC. Pre-treatment neutrophil to lymphocyte ratio (NLR) is a marker of systemic inflammation which has been shown to influence prognosis for patients with mCRPC receiving ketoconazole ${ }^{30}$ and docetaxel. ${ }^{31}$ An ad-hoc analysis of the TROPIC trial demonstrated that patients who developed grade $\geq 3$ neutropenia while receiving cabazitaxel had an improved survival (HR 0.65, 95\%CI 0.43-0.97, $\mathrm{p}=0.035$ ) and that low NLR is also independently associated with improved survival. ${ }^{19}$. However, in the C-EAP cohort, neither NLR nor development of grade $\geq 3$ neutropenia influenced prognosis. No factors analyzed from the CEAP were independently associated with better overall survival.

\section{Predictive Factors}

We did not identify factors independently associated with PSA response in our study. On univariable analysis the presence of visceral disease and development of grade 3-4 neutropenia were associated with PSA response. Visceral disease is a well-documented prognostic factor; ${ }^{17}$ however, visceral disease has not previously been shown to be predictive of response to treatment. Post-hoc analysis of phase III trials of abiraterone and enzalutamide for post-docetaxel mCRPC patients showed that visceral metastases did not impact PSA response. ${ }^{32,33}$ In the CEAP, Gleason score also did not predict response as was shown previously. ${ }^{22}$ The starting dose of cabazitaxel has also been of interest to researchers. The C-EAP population did not have any difference in response for patients who started cabazitaxel with a dose reduction. A recent phase III trial of reduced dose of cabazitaxel $\left(20 \mathrm{mg} / \mathrm{m}^{2}\right.$ vs $\left.25 \mathrm{mg} / \mathrm{m}^{2}\right)$ showed that response and benefit were non-inferior for the lower dose compared to the higher dose. ${ }^{28}$ This study does not support the utility of visceral metastases, Gleason score or starting dose as predictive factors for response to cabazitaxel.

Inflammatory markers have also been investigated for predicting response to treatment. An NLR of less than five has been shown to be predictive of PSA response to abiraterone. ${ }^{34}$ In a subgroup analysis of the TROPIC trial, Lorente et al demonstrated that lower NLR $(\leq 3.0)$ was associated with an improved response to cabazitaxel. ${ }^{35}$ These results were not replicated in the C-EAP population. In this real-world population, this study did not show that lower NLR 
predicted for PSA response. Lorente et al also reported that a change from high to low NLR during treatment was associated with response. However, data from the C-EAP was not available to further investigate this association.

Another clinical factor of interest for predicting response is timing and sequencing of lines of therapy. It has been previously shown that prior abiraterone does not impact the response rate for patients treated with cabazitaxel. ${ }^{23-27}$ The same study also found that prior abiraterone or the duration or response to abiraterone did not influence treatment response to cabazitaxel. This study was done prior to approvals of enzalutamide and radium-223 so these factors could not be addressed. Another important sequencing issue is the time lapsed between receiving docetaxel and cabazitaxel. On univariable analysis, time since last docetaxel use did not significantly change the likelihood of PSA response. Ultimately, this study confirmed some findings about factors which do not influence PSA response or progression but failed to identify factors which would be clinically useful for helping the clinician predict will or will not benefit from cabazitaxel. Therefore, practitioners are left with choosing patients based on clinical trial eligibility as outlined in the TROPIC trial and their clinical judgement.

\section{Limitations}

The results of this study should be considered within the context of several limitations. It is a retrospective study of patients enrolled in a prospective study. The small number of patients included in this study could limit its statistical power to detect smaller differences. LDH was previously identified as a prognostic factor but could not be included in this study due to a high rate of missing values. Performance status is also a strong predictor for prognosis but since most patients included in this study were ECOG 0-1 there was little variability to demonstrate a difference in survival. Furthermore, there have been a number of advances in the treatment of mCRPC since the C-EAP including the introduction of enzalutamide before and after docetaxel, as well as docetaxel and abiraterone for metastatic castrate-sensitive prostate cancer. These changes may influence prognostic and predictive factors for patients receiving cabazitaxel. Future Directions

In this secondary analysis of patients enrolled in the cabazitaxel C-EAP we did not identify any clear clinical factors which predict for survival or PSA response. Cabazitaxel is now more widely available, therefore, larger prospective data registry studies of real-world patients may be feasible for enhancing our understanding which patients benefit the most from cabazitaxel. The landscape for treating metastatic prostate cancer is rapidly changing, therefore, such registries will be valuable sources of information for understanding issues with treatment sequencing in greater detail.

Our results confirm that cabazitaxel is an active agent in mCRPC, but choosing patients for treatment based on clinical factors alone does not appear to be a viable approach. This study, therefore, highlights the need for a deeper understanding of the disease at the molecular level, to facilitate better patient selection. The biomarker driven TAXYNERGY trial looked at an early switch from one taxane to another in patients that were not responding or only partially responding ${ }^{36}$. In this study, a reduction of androgen receptor nuclear localization (ARNL) in 
circulating tumour cells (CTCs) was associated with an increased PSA response. ARNL is a promising biomarker for response or progression in patients receiving taxane therapy. Further assessment of androgen receptor variants in CTCs as biomarkers for response are currently underway (NCT02269982). To complicate matters, published phase 3 trials CHAARTED, ${ }^{37}$ STAMPEDE $^{38,39}$ and LATITUDE ${ }^{40}$ have shown survival benefit for docetaxel and abiraterone in the metastatic castrate-sensitive setting. At this time, little is known about how clinical factors and biomarkers will play a role in choosing the appropriate timing and patient for cabazitaxel. The Prostate Cancer Clinical Trials Working Group’s updated recommendations call for serial analysis of tumor and blood-based biomarkers to be incorporated into clinical trials to better understand prognostic and predictive biomarkers. ${ }^{41}$

\section{Conclusion}

This study failed to reproduce findings from other studies that identified clinical factors associated with survival or PSA response to treatment with cabazitaxel. As previously described, lower hemoglobin was associated with poorer prognosis and prior abiraterone did not influence prognosis or treatment response. This study highlights the difficulty of using clinical factors alone to choose patients for second-line cabazitaxel in the real-world. 


\section{References}

1. Canadian Cancer Society Advisory Committee on Statistics. Canadian cancer statistics 2017. Toronto; 2017.

2. American Cancer Society. Cancer statistics 2017. CA Cancer J Clin 2017;67:7-30.

3. Sridhar SS, Freedland SJ, Gleave ME, et al. Castration-resistant prostate cancer: from new pathophysiology to new treatment. Eur Urol 2014;65:289-99. doi:10.1016/j.eururo.2013.08.008.

4. Attard G, Parker C, Eeles RA, et al. Prostate cancer. Lancet 2015;387:70-82. doi:10.1016/S0140-6736(14)61947-4.

5. Mita A, Denis L, Rowinsky E. Phase I and pharmacokinetic study of XRP6258 (RPR 116258A), a novel taxane, administered as a 1-hour infusion every 3 weeks in patients with advanced. Clin Cancer Res 2009;15:723-30.

6. de Bono JS, Oudard S, Ozguroglu M, et al. Prednisone plus cabazitaxel or mitoxantrone for metastatic castration-resistant prostate cancer progressing after docetaxel treatment: A randomised open-label trial. Lancet 2010;376:1147-54. doi:10.1016/S01406736(10)61389-X.

7. de Bono JS, Logothetis CJ, Molina A, et al. Abiraterone and increased survival in metastatic prostate cancer. N Engl J Med 2011;364:1995-2005. doi:10.1056/NEJMoa1011205.

8. Cabot RC, Harris NL, Rosenberg ES, et al. Increased survival with enzalutamide in prostate cancer after chemotherapy. N Engl J Med 2012;367:1187-97. doi:10.1056/NEJMoa1207506.

9. Parker C, Nilsson S, Heinrich D, et al. Alpha emitter radium-223 and survival in metastatic prostate cancer. N Engl J Med 2013;369:213-23.

10. Smaletz O, Scher HI, Small EJ, et al. Nomogram for overall survival of patients with progressive metastatic prostate cancer after castration. J Clin Oncol 2002;20:3972-82.

11. Pond GR, Sonpavde G, de Wit R, et al. The prognostic importance of metastatic site in men with metastatic castration-resistant prostate cancer. Eur Urol 2014;65:3-6. doi:10.1016/j.eururo.2013.09.024.

12. Halabi S, Small EJ, Kantoff PW, et al. Prognostic model for predicting survival in men with hormone-refractory metastatic prostate cancer. J Clin Oncol 2003;21:1232-7.

13. Armstrong AJ, Tannock IF, de Wit R, et al. The development of risk groups in men with metastatic castration-resistant prostate cancer based on risk factors for PSA decline and survival. Eur J Cancer 2010;46:517-25. doi:10.1016/j.ejca.2009.11.007.

14. Armstrong AJ, Garrett-Mayer E, de Wit R, et al. Prediction of survival following first-line chemotherapy in men with castration-resistant metastatic prostate cancer. Clin Cancer Res 2010;16:203-11. doi:10.1158/1078-0432.CCR-09-2514.

15. Armstrong AJ, Garrett-Mayer ES, Yang Y-CO, et al. A contemporary prognostic nomogram for men with hormone-refractory metastatic prostate cancer: a TAX327 study 
analysis. Clin Cancer Res 2007;13:6396-403. doi:10.1158/1078-0432.CCR-07-1036.

16. Halabi S, Lin C-Y, Kelly WK, et al. Updated prognostic model for predicting overall survival in first-line chemotherapy for patients with metastatic castration-resistant prostate cancer. J Clin Oncol 2014;32:671-7. doi:10.1200/JCO.2013.52.3696.

17. Halabi S, Kelly WK, Ma H, et al. Meta-analysis evaluating the impact of site of metastasis on overall survival in men with castration-resistant prostate cancer. J Clin Oncol 2016;34:1652-9. doi:10.1200/JCO.2015.65.7270.

18. Halabi S, Lin C-Y, Small EJ, et al. Prognostic model predicting metastatic castrationresistant prostate cancer survival in men treated with second-line chemotherapy. $J$ Natl Cancer Inst 2013;105:1729-37. doi:10.1093/jnci/djt280.

19. Meisel A, von Felten S, Vogt DR, et al. Severe neutropenia during cabazitaxel treatment is associated with survival benefit in men with metastatic castration-resistant prostate cancer (mCRPC): A post-hoc analysis of the TROPIC phase III trial. Eur J Cancer 2016;56:93100. doi:10.1016/j.ejca.2015.12.009.

20. Uemura K, Kawahara T, Yamashita D, et al. Neutrophil-to-lymphocyte ratio predicts prognosis in castration-resistant prostate cancer patients who received cabazitaxel chemotherapy. Biomed Res Int 2017;ePub. doi:10.1155/2017/7538647.

21. Antonarakis ES, Lu C, Luber B, et al. Androgen receptor splice variant 7 and efficacy of taxane chemotherapy in patients with metastatic castration-resistant prostate cancer. JAMA Oncol 2015;1:582-91. doi:10.1001/jamaoncol.2015.1341.

22. Buonerba C, Pond GR, Sonpavde G, et al. Potential value of Gleason score in predicting the benefit of cabazitaxel in metastatic castration-resistant prostate cancer. Future Oncol 2013;9:889-97. doi:10.2217/fon.13.39.

23. Pezaro CJ, Omlin AG, Altavilla A, et al. Activity of cabazitaxel in castration-resistant prostate cancer progressing after docetaxel and next-generation endocrine agents. Eur Urol 2014;66:459-65. doi:10.1016/j.eururo.2013.11.044.

24. Al Nakouzi N, Le Moulec S, Albigès L, et al. Cabazitaxel remains active in patients progressing after docetaxel followed by novel androgen receptor pathway targeted therapies. Eur Urol 2015;68:228-35. doi:10.1016/j.eururo.2014.04.015.

25. van Soest RJ, Nieuweboer AJM, de Morrée ES, et al. The influence of prior novel androgen receptor targeted therapy on the efficacy of cabazitaxel in men with metastatic castration-resistant prostate cancer. Eur J Cancer 2015;51:2562-9. doi:10.1016/j.ejca.2015.07.037.

26. Saad F, Winquist E, Hubay S, et al. Efficacy, quality of life, and safety of cabazitaxel in Canadian metastatic castration-resistant prostate cancer patients treated or not with prior abiraterone. Can Urol Assoc J 2016;10:102-9. doi:10.5489/cuaj.3470.

27. Bando Y, Hinata N, Terakawa T, et al. Activity of cabazitaxel in patients with metastatic castration-resistant prostate cancer after treatment with single or dual regimens of novel androgen receptor-targeting agents. Med Oncol 2017;34:163. doi:10.1007/s12032-0171024-0. 
28. Eisenberger M, Hardy-Bessard A-C, Kim CS, et al. Phase III study comparing a reduced dose of cabazitaxel $\left(20 \mathrm{mg} / \mathrm{m}^{2}\right)$ and the currently approved dose $\left(25 \mathrm{mg} / \mathrm{m}^{2}\right)$ in postdocetaxel patients with metastatic castration-resistant prostate cancer-PROSELICA. J Clin Oncol 2017;35:3198-206. doi:10.1200/JCO.2016.72.1076.

29. Scher HI, Halabi S, Tannock I, et al. Design and end points of clinical trials for patients with progressive prostate cancer and castrate levels of testosterone: recommendations of the Prostate Cancer Clinical Trials Working Group. J Clin Oncol 2008;26:1148-59. doi:10.1200/JCO.2007.12.4487.

30. Keizman D, Gottfried M, Ish-Shalom M, et al. Pretreatment neutrophil-to-lymphocyte ratio in metastatic castration-resistant prostate cancer patients treated with ketoconazole: association with outcome and predictive nomogram. Oncologist 2012;17:1508-14. doi:10.1634/theoncologist.2012-0125.

31. Nuhn P, Vaghasia AM, Goyal J, et al. Association of pretreatment neutrophil-tolymphocyte ratio (NLR) and overall survival (OS) in patients with metastatic castrationresistant prostate cancer (mCRPC) treated with first-line docetaxel. BJU Int 2014;114:E11-7. doi:10.1111/bju.12531.

32. Goodman OB, Flaig TW, Molina A, et al. Exploratory analysis of the visceral disease subgroup in a phase III study of abiraterone acetate in metastatic castration-resistant prostate cancer. Prostate Cancer Prostatic Dis 2014;17:34-9. doi:10.1038/pcan.2013.41.

33. Evans CP, Higano CS, Keane T, et al. The PREVAIL study: primary outcomes by site and extent of baseline disease for enzalutamide-treated men with chemotherapy-naïve metastatic castration-resistant prostate cancer. Eur Urol 2016;70:675-83. doi:10.1016/j.eururo.2016.03.017.

34. Leibowitz-Amit R, Templeton AJ, Omlin A, et al. Clinical variables associated with PSA response to abiraterone acetate in patients with metastatic castration-resistant prostate cancer. Ann Oncol 2014;25:657-62. doi:10.1093/annonc/mdt581.

35. Lorente D, Mateo J, Templeton AJ, et al. Baseline neutrophil-lymphocyte ratio (NLR) is associated with survival and response to treatment with second-line chemotherapy for advanced prostate cancer independent of baseline steroid use. Ann Oncol 2015;26:750-5. doi:10.1093/annonc/mdu587.

36. Antonarakis ES, Tagawa ST, Galletti G, et al. Randomized, noncomparative, phase II trial of early switch from docetaxel to cabazitaxel or vice versa, with integrated biomarker analysis, in men with chemotherapy-naïve, metastatic, castration-resistant prostate cancer. J Clin Oncol 2017;35:3181-8. doi:10.1200/JCO.2017.72.4138.

37. Sweeney CJ, Chen Y-H, Carducci M, et al. Chemohormonal therapy in metastatic hormone-sensitive prostate cancer. N Engl J Med 2015;373:737-46. doi:10.1056/NEJMoa1503747.

38. James ND, Sydes MR, Clarke NW, et al. Addition of docetaxel, zoledronic acid, or both to first-line long-term hormone therapy in prostate cancer (STAMPEDE): survival results from an adaptive, multiarm, multistage, platform randomised controlled trial. Lancet 
2015;387:1163-77. doi:10.1016/S0140-6736(15)01037-5.

39. James ND, de Bono JS, Spears MR, et al. Abiraterone for prostate cancer not previously treated with hormone therapy. $N$ Engl J Med 2017;377:338-51.

doi:10.1056/NEJMoa1702900.

40. Fizazi K, Tran N, Fein L, et al. Abiraterone plus prednisone in metastatic, castrationsensitive prostate cancer. $N$ Engl J Med 2017;377:352-60. doi:10.1056/NEJMoa1704174.

41. Scher HI, Morris MJ, Stadler WM, et al. Trial design and objectives for castrationresistant prostate cancer: Updated recommendations from the prostate cancer clinical trials working group 3. J Clin Oncol 2016;34:1402-18. doi:10.1200/JCO.2015.64.2702. 


\section{Figures and Tables}

Box 1. Clinical variables analyzed for prognostic and predictive significance.

Patient and disease factors: Age (continuous) - at start of cabazitaxel, BMI (continuous), ECOG performance status (categorical 0-1 vs 2), active pain ( $\mathrm{Y} / \mathrm{N}$ ), Gleason score (continuous), and site of metastases: visceral (Y/N) or bone-only (Y/N)

Treatment factors: Duration of hormonal use (continuous), number of cycles of docetaxel (continuous), time since last docetaxel treatment (continuous), prior use of abiraterone (Y/N), abiraterone duration (continuous), response to abiraterone (Y/N), starting dose of cabazitaxel (25 vs $<25$ ), primary prophylactic use of G-CSF (Y/N), dose delays ( $0 \mathrm{vs} \geq 1)$, dose reductions (Y/N), neutropenia (no grade 3-4 vs grade 3-4 or febrile neutropenia), any toxicity (no grade 3-4 vs grade 3-4)

Laboratory variables (at time of starting cabazitaxel): PSA (continuous), hemoglobin (continuous), neutrophil to lymphocyte ratio ( $\geq 3.0 \mathrm{vs}<3.0$ ), lactate dehydrogenase (continuous), alkaline phosphatase (continuous)

BMI: body mass index; ECOG: Eastern Cooperative Oncology Group; G-CSF: granulocyte colony-stimulating Factor; PSA: prostate-specific antigen. 


\begin{tabular}{|c|c|}
\hline & $n=45$ \\
\hline \multicolumn{2}{|l|}{ Baseline characteristics } \\
\hline Age, years, median (range) & $65(47-81)$ \\
\hline Body mass index, median (range) & $27.1(17.6-39.3)$ \\
\hline \multicolumn{2}{|l|}{ ECOG performance status (\%) } \\
\hline 0 & 15 (33.3) \\
\hline 1 & $26(57.8)$ \\
\hline 2 & $4(8.9)$ \\
\hline Presence of pain (\%) & 31 (68.9) \\
\hline Gleason score, median (range) & $8(6-10)$ \\
\hline Measurable disease (\%) & $33(71.1)$ \\
\hline Visceral metastases (\%) & $10(22.2)$ \\
\hline Bone-only disease (\%) & $26(57.8)$ \\
\hline $\begin{array}{l}\text { Duration of hormonal treatment, years, median } \\
\text { (range) }\end{array}$ & $3.7(0.3-18.3)$ \\
\hline Number of cycles of docetaxel, median (range) & $6(1-27)$ \\
\hline $\begin{array}{l}\text { Time since dose of docetaxel, months, median } \\
\text { (range) }\end{array}$ & $9.4(0.7-56.8)$ \\
\hline Prior use of abiraterone (\%) & 15 (33.3) \\
\hline $\begin{array}{l}\text { Duration of use of abiraterone, months, median } \\
\text { (range) }\end{array}$ & $8.1(2.3-34.7)$ \\
\hline Response to abiraterone (\%) & $61.1 \%$ \\
\hline Starting dose of cabazitaxel $25 \mathrm{mg} / \mathrm{m}^{2}(\%)$ & $100 \%$ \\
\hline Primary prophylactic use of G-CSF (\%) & $23(53.5)$ \\
\hline One or more dose delays (\%) & $51.2 \%$ \\
\hline Dose reduction (\%) & $27.9 \%$ \\
\hline PSA, ng/mL, median (range) & $249.7(13.6-4428)$ \\
\hline Hemoglobin, g/dL, median (range) & $115(90-149)$ \\
\hline Neutrophil-to-lymphocyte ratio $\geq 3(\%)$ & $4.40(1.20-19.00)$ \\
\hline Lactate dehydrogenase, median (range) & $263(121-970)$ \\
\hline Alkaline phosphatase, IU/L, median (range) & $125(49-4141)$ \\
\hline \multicolumn{2}{|l|}{ Treatment exposure } \\
\hline Cycles of cabazitaxel, median (range) & $6(1-27)$ \\
\hline \multicolumn{2}{|l|}{ Best PSA response, n (\%): } \\
\hline \multirow{3}{*}{$\begin{array}{l}\text { Response } \\
\text { Stable disease } \\
\text { Progressive disease }\end{array}$} & $19(42.2)$ \\
\hline & $14(31.1)$ \\
\hline & $9(20.0)$ \\
\hline
\end{tabular}




\begin{tabular}{|l|c|}
\hline Not evaluable & 3 (6.7) \\
\hline Overall survival, months, median (range) & 11.3 (3.4-unknown) \\
\hline Toxicity (Grade $\geq 3$, frequency $\geq 2 \%$ ) & \\
\hline Any & $34(75.6)$ \\
\hline Neutropenia & $10(22.2)$ \\
\hline Febrile neutropenia & $6(13.3)$ \\
\hline Anemia & $6(13.3)$ \\
\hline Fatigue & $4(8.9)$ \\
\hline Diarrhea & $7(15.6)$ \\
\hline
\end{tabular}

Abbreviations: ECOG: Eastern Cooperative Oncology Group; (G-CSF: granulocyte colonystimulating factor; PSA: prostate-specific antigen.

\begin{tabular}{|l|c|c|c|c|}
\hline \multirow{5}{|l|}{$\begin{array}{l}\text { Table 2. Univariable and multivariable analysis of clinical factors associated with overall } \\
\text { survival }\end{array}$} & \multicolumn{2}{|c|}{ Univariable analysis } & Final multivariable model \\
\hline & HR (95\% CI) & p & HR (95\% CI) & p \\
\hline Factor & $0.97(0.76-1.18)$ & 0.806 & & \\
\hline Age (per decrease in 5 years) & $0.97(0.91-1.03)$ & 0.322 & & \\
\hline BMI & $0.75(0.22-2.50)$ & 0.641 & & \\
\hline ECOG & $1.45(0.73-2.89)$ & 0.292 & & \\
\hline Presence of pain & $0.97(0.66-1.41)$ & 0.860 & & \\
\hline Gleason score & $0.99(0.48-2.08)$ & 0.989 & & \\
\hline Visceral disease & $1.10(0.55-2.22)$ & 0.785 & & \\
\hline Bone-only disease & $1.00(0.99-1.01)$ & 0.719 & & \\
\hline $\begin{array}{l}\text { Duration of hormone treatment } \\
\text { (per 1 year) }\end{array}$ & & & & \\
\hline Number of cycles of docetaxel & $0.94(0.84-1.06)$ & 0.329 & & \\
\hline $\begin{array}{l}\text { Time since last dose of } \\
\text { docetaxel (per 1 month) }\end{array}$ & $0.96(0.91-1.01)$ & 0.088 & $0.99(0.93-1.05)$ & \\
\hline Prior use of abiraterone & $0.86(0.44-1.65)$ & 0.649 & & \\
\hline $\begin{array}{l}\text { Duration of use of abiraterone } \\
\text { (per 1 month) }\end{array}$ & $1.00(1.00-1.00)$ & 0.233 & & \\
\hline Response to abiraterone & $0.87(0.33-2.28)$ & 0.775 & & \\
\hline $\begin{array}{l}\text { Primary prophylactic use of G- } \\
\text { CSF }\end{array}$ & $0.75(0.39-1.43)$ & 0.377 & & \\
\hline One or more dose delays & $0.79(0.40-1.56)$ & 0.494 & & \\
\hline Dose reduction & $0.53(0.24-1.17)$ & 0.118 & & \\
\hline Grade 3-4 neutropenia & $0.70(0.33-1.48)$ & 0.350 & & \\
\hline Any grade 3-4 toxicity & $2.72(1.17-6.33)$ & 0.020 & $0.66(0.25-1.77)$ & \\
\hline
\end{tabular}




\begin{tabular}{|l|c|c|c|c|}
\hline PSA (per increase in 10 units) & $1.00(1.00-1.00)$ & 0.660 & & 0.047 \\
\hline $\begin{array}{l}\text { Hemoglobin (per decrease in } 10 \\
\text { units) }\end{array}$ & $1.41(1.15-1.66)$ & 0.009 & $1.33(1.05-1.62)$ & \\
\hline Neutrophil-to-lymphocyte ratio & $0.97(0.44-2.13)$ & 0.943 & & \\
\hline $\begin{array}{l}\text { Alkaline phosphatase (per } \\
\text { increase in 10 units) }\end{array}$ & $1.00(1.00-1.01)$ & 0.376 & & \\
\hline
\end{tabular}

BMI: body mass index; ECOG: Eastern Cooperative Oncology Group; G-CSF: granulocyte colony-stimulating factor; PSA: prostate-specific antigen.

\begin{tabular}{|c|c|c|c|c|}
\hline \multirow[t]{2}{*}{ Factor } & \multicolumn{2}{|c|}{ Univariable analysis } & \multicolumn{2}{|c|}{$\begin{array}{c}\text { Final multivariable } \\
\text { model }\end{array}$} \\
\hline & HR (95\% CI) & $\mathbf{p}$ & HR (95\% CI) & $\mathbf{p}$ \\
\hline Age (per decrease in 5 years) & $0.80(0.38-1.21)$ & 0.286 & & \\
\hline BMI & $0.93(0.81-1.06)$ & 0.262 & & \\
\hline ECOG & $0.58(0.05-6.98)$ & 0.670 & & \\
\hline Presence of pain & $0.76(0.20-2.93)$ & 0.695 & & \\
\hline Gleason score & $1.20(0.65-2.22)$ & 0.565 & & \\
\hline Visceral disease & $4.85(0.85-27.70)$ & 0.076 & $\begin{array}{c}3.6(0.57- \\
23.1) \\
\end{array}$ & 0.17 \\
\hline Bone-only disease & $0.60(0.17-2.14)$ & 0.431 & & \\
\hline $\begin{array}{l}\text { Duration of hormone } \\
\text { treatment }\end{array}$ & $1.00(0.98-1.01)$ & 0.533 & & \\
\hline $\begin{array}{l}\text { Number of cycles of } \\
\text { docetaxel }\end{array}$ & $1.09(0.89-1.33)$ & 0.421 & & \\
\hline Time since dose of docetaxel & $0.93(0.85-1.02)$ & 0.117 & & \\
\hline Prior use of abiraterone & $1.94(0.56-6.79)$ & 0.298 & & \\
\hline $\begin{array}{l}\text { Duration of use of } \\
\text { abiraterone }\end{array}$ & $1.00(1.00-1.00)$ & 0.352 & & \\
\hline Response to abiraterone & $0.89(0.12-6.31)$ & 0.906 & & \\
\hline $\begin{array}{l}\text { Primary prophylactic use of } \\
\text { G-CSF }\end{array}$ & $4.06(1.12-14.80)$ & 0.034 & $\begin{array}{l}2.1(0.46- \\
9.81)\end{array}$ & 0.33 \\
\hline One or more dose delays & $1.21(0.36-4.10)$ & 0.76 & & \\
\hline Dose reduction & $1.66(0.42-6.64)$ & 0.472 & & \\
\hline
\end{tabular}




\begin{tabular}{|l|c|c|c|c|}
\hline Grade 3-4 neutropenia & $6.12(1.10-34.35)$ & 0.039 & $\begin{array}{c}3.4(0.47- \\
25.1)\end{array}$ & 0.23 \\
\hline Any grade 3-4 toxicity & $0.77(0.20-2.93)$ & 0.695 & & \\
\hline PSA (per unit of 10) & $1.00(0.99-1.06)$ & 0.324 & & \\
\hline $\begin{array}{l}\text { Hemoglobin (per decrease in } \\
10 \text { units) }\end{array}$ & $1.30(0.87-1.74)$ & 0.234 & & \\
\hline $\begin{array}{l}\text { Neutrophil-to-lymphocyte } \\
\text { ratio }\end{array}$ & $0.79(0.17-3.69)$ & 0.764 & & \\
\hline $\begin{array}{l}\text { Alkaline phosphatase (per } \\
\text { increase in 10 units) }\end{array}$ & $\begin{array}{c}1.0007(1.000 .99- \\
1.0114)\end{array}$ & 0.149 & & \\
\hline & & & & \\
\hline
\end{tabular}

BMI: body mass index; ECOG: Eastern Cooperative Oncology Group; G-CSF: granulocyte colony-stimulating factor; PSA: prostate-specific antigen. 


\begin{tabular}{|l|c|c|c|c|}
\hline \multirow{2}{*}{$\begin{array}{l}\text { Table 4. Univariable analysis of clinical factors predicting for PSA progression } \\
\text { (multivariable model was not performed due to few events) }\end{array}$} \\
\hline \multirow{2}{*}{ Factor } & \multicolumn{2}{|c|}{ Univariable analysis } & \multicolumn{2}{c|}{ Final multivariable model } \\
\cline { 2 - 5 } & OR (95\% CI) & p & OR (95\% CI) & P \\
\hline Age (per decrease in 5 years) & $1.39(0.90-1.89)$ & 0.19 & & \\
\hline BMI & $1.06(0.90-1.25)$ & 0.48 & & \\
\hline ECOG & $9.14(0.72-115.5)$ & 0.09 & & \\
\hline Presence of pain & $1.52(0.27-8.65)$ & 0.64 & & \\
\hline & & & & \\
\hline Gleason score & $1.05(0.50-2.18)$ & 0.90 & & \\
\hline Visceral disease & $0.46(0.05-4.36)$ & 0.50 & & \\
\hline Bone-only disease & $1.40(0.31-6.24)$ & 0.66 & & \\
\hline & & & & \\
\hline Duration of hormone treatment & $1.00(0.98-1.02)$ & 0.89 & & \\
\hline Number of cycles of docetaxel & $0.95(0.79-1.15)$ & 0.61 & & \\
\hline Time since dose of docetaxel & $1.13(0.97-1.32)$ & 0.12 & & \\
\hline Prior use of abiraterone & $0.10(0.01-0.87)$ & 0.04 & & \\
\hline Duration of use of abiraterone & $1.00(1.00-1.00)$ & 0.55 & & \\
\hline Response to abiraterone & $0.28(0.02-3.88)$ & 0.34 & & \\
\hline $\begin{array}{l}\text { Primary prophylactic use of G- } \\
\text { CSF }\end{array}$ & $0.08(0.01-0.73)$ & 0.03 & & \\
\hline One or more dose delays & $0.42(0.09-1.95)$ & 0.27 & & \\
\hline Dose reduction & $0.29(0.03-2.61)$ & 0.27 & & \\
\hline Any grade 3-4 toxicity & $1.52(0.27-8.65)$ & 0.64 & & \\
\hline & & & & \\
\hline PSA (per increase in 10 units) & $1.02(1.01-1.03)$ & 0.65 & & \\
\hline Hemoglobin (per decrease in 10 & $0.75(0.21,1.29)$ & 0.30 & & \\
units) & & & & \\
\hline $\begin{array}{l}\text { Alkaline phosphatase (per } \\
\text { increase in 10 units) }\end{array}$ & $1.00(0.99-1.01)$ & 0.91 & & \\
\hline BMI: body mass & & & & \\
\hline
\end{tabular}

BMI: body mass index; ECOG: Eastern Cooperative Oncology Group; G-CSF: granulocyte colony-stimulating factor; PSA: prostate-specific antigen. 